Revista de Ciencias Sociales - Número 62 (2013) - Páginas 49-73

Incesto, memoria y legítima defensa con resultado de muerte:...

\title{
INCESTO, MEMORIA Y LEGÍTIMA DEFENSA CON RESULTADO DE MUERTE: UNA MIRADA DESDE LA PELÍCULA “VOLVER" Y EL GÉNERO
}

\author{
INCEST, MEMORY AND THE RIGHT OF SELF-DEFENSE \\ WITH DEATH RESULT: A VIEW FROM THE FILM \\ "VOLVER" AND THE GENDER
}

\author{
JUAN PAULO MARCHANT ESPINOZA* \\ Programa de Magíster \\ Centro de Estudio de Género y Cultura en América Latina \\ Universidad de Chile, Chile \\ jpaulo.marchant@gmail.com
}

\section{Resumen}

El presente trabajo pretende abordar los conceptos de incesto, cripta traumática y legítima defensa con resultado de muerte para describir la relación que se forja entre ellos, desde una perspectiva de género, utilizando como sustrato de información y análisis la película Volver de Pedro Almodóvar filmada el año 2006. Lo anterior, debido a que un evento traumático produce diversos grados de daño en la memoria de los sujetos, por lo que visibilizar esta temática se vuelve un aporte para futuras líneas de trabajo en esta materia.

* Profesional Área Psicosocial, Unidad Prevención de Violencia Contra la Mujer - Programa Chile Acoge, SERNAM. Psicólogo, FACSO-U. Chile. Magíster (C) en Estudios de Género y Cultura, Mención Humanidades, CEGECAL-U. Chile. Postítulo en Psicoterapia Humanista Existencial, FACSO-U. Chile. Bachiller en Ciencias Sociales y Humanidades, U. Chile. Artículo recibido el 22 de julio de 2012 y aceptado el 14 de septiembre de 2012.

Revista de Ciencias Sociales - Número 62 (2013) - Universidad de Valparáíso - ISSN 0716-7725-Valparaíso, Chile 
Finalmente, es importante considerar que este ensayo busca discutir el concepto jurídico de legítima defensa frente al incesto, incluso cuando una de esas consecuencias es la muerte del agresor, donde se produce un segundo evento traumático en la potencial/eventual víctima.

\section{Palabras Claves} sexual.

Incesto paterno, dinámica familiar, memoria; derecho, género, abuso

\section{Abstract}

This paper discusses the concepts of incest, trauma and self-defence resulting in death to describe the relationship that is forged between them. This, from a gender perspective and using information from the Pedro Almodóvar's film Volver (2006). This, because a traumatic event causes varying degrees of damage to the memory of the subject, so this issue becomes visible a contribution to future works in this area. Finally, it is important that this essay seeks to discuss the legal concept of self-defence against incest, even when one of those consequences is the death of the aggressor, which produces a second traumatic event in the potential / possible victim.

\section{Keywords}

Parental incest, family dynamics, memory, law, gender, sexual abuse.

\section{Planteamiento}

El abuso sexual en niños como fenómeno de maltrato no es un acto reciente, sino que poco considerado en la época de antaño. Esto, debido a que sólo en el año 1905, con la figura de Freud, se reconoció el concepto de sexualidad infantil ${ }^{1}$ y se profundizó en su estudio. En sintonía con lo anterior, cabe señalar que Chile ratificó la Convención Internacional de los Derechos del Niño en el año 1990, antes de esa

1. Martínez, 2000; López Sánchez, 2000 y Capella., 2003, citados en QUIRÓS, Paula: Comparación de las dinámicas familiares en familias que presentan abuso sexual con otros tipos de familia. Tesis para optar al grado de Magíster en Psicología, Facultad de Ciencias Sociales, Santiago, Universidad de Chile, 2006.

Facultad de Derecho y Ciencias Sociales - Universidad de Valparaíso - Chile 
fecha, el ámbito de lo sexual en la infancia era terreno pedregoso y ambiguo $^{2}$.

Hablar de incesto, memoria y vulneración de derechos representa traer al tapete, un tema cuyas consecuencias psicológicas y sociales son de grandes proporciones. Ello porque se refiere a "toda relación sexual de tipo abusiva, sin importar la clase de contacto realizado, establecida por un padre, padrastro, conviviente de la madre o cualquier persona que ejerce el rol paternal, contra uno o varios niños(as) a su cargo"”.

Para efectos de este trabajo, considerando su objeto de análisis y el concepto de memoria, resulta interesante detenerse un momento en el término incesto exogámico, que se refiere al abuso realizado por sujetos no relacionados genéticamente, sino pertenecientes a la familia extensa como puede ser el caso de un padrastro ${ }^{4}$. Esta situación afecta no sólo a una persona en particular, sino que a todos los miembros de la familia, toda vez que esta se vuelve disfuncional dado que se desea mantener en secreto lo ocurrido, silenciando el hecho, encriptándolo ${ }^{5}$.

El objetivo de este trabajo es abrir la discusión respecto al concepto jurídico de legítima defensa frente al incesto, incluso cuando la consecuencia de dicha acción es la muerte del agresor. Dado que tras este hecho, se produce un segundo evento traumático en la potencial/

2. CAPELLA, Claudia y MIRANDA, Jennifer: Diseño, implementación y evaluación piloto de una intervención psicoterapéutica grupal para niños y niñas víctimas de abuso sexual. Tesis para optar al título de psicólogo, Facultad de Ciencias Sociales, Santiago, Universidad de Chile, 2003.

3. BECAR, Carolina e IBACETA, Francisco: Abuso sexual incestuoso y sistema judicial: Obligatoriedad de la denuncia o estrategia y opción de intervención psicosociolegal. Memoria para optar al título de psicólogo, Facultad de Ciencias Sociales, Santiago, Universidad de Chile, 2000. Pág. 29.

4. QUIRÓS, Paula: Op. Cit.

5. NAVARRO, Carolina: Patrones de vinculación en madres de víctimas de abusos incestuosos: Los peligros del vínculo. Tesis para optar al título de psicólogo, Facultad de Ciencias Sociales, Santiago, Universidad de Chile, 1998 y QUIRÓS, Paula: Op. Cit.

Revista de Ciencias Sociales - Número 62 (2013) - Universidad de Valparáiso - ISSN 0716-7725-Valparáís, Chile 
eventual víctima, ya que sus derechos son nuevamente vulnerados. En este sentido, ocurre una victimización secundaria, pues, primero, alguien intenta agredirla y luego, podría ser desacreditada y acusada de un delito.

Lo anterior, dado que podría resultar de interés académico y profesional para quienes se desempeñan en el área psico-jurídica cuestionar cómo aborda la justicia esta problemática, aportando diversas visiones desde el ámbito del género en esta materia. Esto último, considerando el evento que da sustento al presente ensayo: Paco, el marido de Raimunda, intenta violar a Paula, hija de ésta, quien lo amenaza con un cuchillo. Él piensa que no lo va a atacar, pero lo apuñala y asesina. Cuando llega su madre y descubre el hecho, decide esconder el cadáver, aunque antes le cuenta que él no era su verdadero padre y que en otro momento le dirá toda la verdad.

Finalmente, lo expuesto hasta el momento, permite hipotetizar que el incesto, mediante la prohibición de develarlo, sostiene el establecimiento de una cripta que opera como escalada de violencia y complicidad frente a posibles ataques. Por tanto, considerando esta premisa, se busca responder a la interrogante: ¿Cómo se relacionan los conceptos de incesto paterno-filial, cripta traumática y legítima defensa con resultado de muerte ante situaciones de agresión sexual?

\section{Objetivos}

\subsection{Objetivo General}

Describir las implicancias de la relación que existe entre incesto paterno-filial, cripta traumática y el concepto de legítima defensa con resultado de muerte ante la problemática de una agresión sexual.

\subsection{Objetivos Específicos}

1. Conocer y analizar el concepto de incesto, sus efectos y legislación en Chile.

2. Describir y analizar el concepto de trauma y memoria en relación a la temática de abuso sexual.

Facultad de Derecho y Ciencias Sociales - Universidad de Valparaíso - Chile 
3. Analizar el concepto jurídico de legítima defensa así como, otros atingentes a la materia.

4. Analizar la película de Pedro Almodóvar, "Volver", buscando ligar el fenómeno de la agresión sexual con su impacto en las diversas generaciones de una misma familia.

\section{Marco Teórico}

\subsection{Concepto de incesto}

El primer acercamiento a los estudios sobre incesto y su posterior prohibición, se relacionan con la figura de Freud ${ }^{6}$, quien centró su atención en dos fenómenos: totemismo y tabú del incesto. Esto último, se entiende como la prohibición de casarse dentro de un mismo linaje, con lo cual se fomenta la exogamia entre diversos grupos y la unión entre familias.

Por otra parte, cabe señalar que cuando los miembros de la sociedad incumple esta idea de intercambio sanguíneo y relacional entre grupos, que debería ser por todos respetada, nace una situación de ribetes devastadores para la construcción psíquica de los afectados: El incesto. Este fenómeno, que suele iniciarse en la infancia y prolongarse hasta la adolescencia, puede entenderse como: "todo contacto de tipo sexual realizado en forma voluntaria por un adulto que es pariente de la víctima"'.

Respecto a la dinámica que se establece entre el abusador y su víctima, cabe mencionar que esta relación desigual se encuentra protegida por el secreto y la ley del silencio, como una forma de autorregulación homeostática del sistema familiar, por lo que una vez que emerge a la luz pública colapsa y sobreviene su posterior declive, mediado por un trato diferenciado hacia la víctima, procesos de

6. FREUD, Sigmund: Tótem y tabú. Madrid, Alianza, 1988.

7. DUARTE, Diana, et. al.: Análisis e interpretación de los resultados de un caso complejo de mezcla de ADN (incesto endogámico), Ponencia presentada en: "III Congreso Brasilero de Genética Forense y II Jornada Latinoamericana de Genética Forense", 10-13 de mayo, PUCRS, Porto Alegre, Brasil, 2011. Pág. 1.

Revista de Ciencias Sociales - Número 62 (2013) - Universidad de Valparáíso - ISSN 0716-7725-Valparaíso, Chile 
intimidación, presiones psicológicas e incredulidad de la denuncia por el resto de la población ${ }^{8}$.

Cabe mencionar que existe una estrecha relación entre los roles de género, las relaciones de poder y el incesto. Esto último, dado que el padre al cometer el abuso, rompe con los cánones de hombre protector y agente de cuidado 9 . Asimismo, debido a la constante interacción padrehija, se instaura una relación perversa de sometimiento y docilización corporal, mediatizada, por el silencio y control de las futuras acciones. Siguiendo a Foucault ${ }^{10}$, se ha logrado controlar no sólo la voluntad, sino que también el cuerpo y, por tanto, el padre podrá anticiparse o actuar ante "las acciones eventuales o actuales, presentes o futuras" ${ }^{11} \mathrm{de}$ su hijo-hija/víctima, evitando o dilatando la develación de lo ocurrido a través de la coerción y chantaje psico-afectivo.

Es importante destacar en sintonía con el párrafo anterior, que el hecho que sea el padre quien comete el abuso, es una traición a su responsabilidad social, toda vez que mediante la sexualización de la relación con su hijo/a descalifica las funciones parentales tanto en su dimensión simbólica como humana ${ }^{12}$. Dicha situación, es posible debido

8. BARUDY, Jorge: Maltrato Infantil, Ecología Social: Prevención y Reparación. Santiago, Editorial Galdoc, 1998 y ABARZA, Pamela y OLIVARES, Alejandra: Estudio exploratorio descriptivo de interacciones del sistema familiar en familias con abuso sexual infantil. Tesis para optar al título de psicólogo, Facultad de Ciencias Sociales, Santiago, Universidad de Chile, 2000.

9. CONNELL, Robert: "La organización social de la masculinidad”. En: Valdés, Teresa y Olavarría, José (Eds). Masculinidades, Poder y Crisis. Santiago de Chile, Isis Internacional / FLACSO, 1997. Págs. 31-48 y GIBERTI, Eva y FERNÁNDEZ, Ana María (Comp.): La mujer y la violencia invisible. Buenos Aires, Editorial Sudamericana, 1989.

10. FOUCAULT, Michel: Vigilary castigar: nacimiento de la prisión (1 ${ }^{\mathrm{a}} \mathrm{ed}$.). Buenos Aires, Siglo XXI Editores, 2002.

11. FOUCAULT, Michel: "El sujeto y el poder". En: Revista Mexicana de Sociología, Vol. 50, No 3, 1988, Págs. 3-20. P. 4.

12. GIBERTI, Eva y FERNÁNDEZ, Ana María (Comp.): Op. Cit. GIBERTI, Eva: Incesto paterno-filial: una visión multidisciplinaria: perspectivas históricas, psicológicas, jurídicas y forenses. Buenos Aires, Editorial La Universidad, 1998.

Facultad de Derecho y Ciencias Sociales - Universidad de Valparaíso - Chile 
a que el abusador se ampara bajo la figura de autoridad que le entrega el seno familiar y social, siendo precisamente aquel "grado de institucionalización (sin el cual no se atrevería a mandar) el que permite la dominación que evoca la relación directa entre el amo y el servidor"13.

Finalmente, es dicha relación directa entre amo y servidor enunciada por $\operatorname{Aron}^{14}$, la que permite sostener, siguiendo a Giberti ${ }^{15}$, que el incesto es la primera instancia donde se inaugura la servidumbre sexual al varón por parte de la mujer, amparada en la imposición y consolidación de las relaciones de dominación y desigualdad.

\subsection{Memoria y Trauma}

Toda situación de incesto es un hecho devastador para el psiquismo, cuyos efectos a futuro podrían devenir en una patología ${ }^{16}$. En relación con esto último, se está frente a lo que Martín-Baró ${ }^{17}$ define como Trauma Psicosocial, es decir, una herida vivenciada que afecta al sujeto y lo marca con un residuo negativo, la cual tiene un carácter dialéctico porque es causada por un hecho social, que afecta a comunidad en su conjunto, pero que repercute en cada persona según su propia subjetividad.

Ahora bien, antes de hablar de trauma, es preciso definir un concepto fundamental: Memoria. Para ello, es necesario realizar una distinción entre cada tipo, vale decir, aquella que alude a lo individual y a lo colectivo. En primer término, siguiendo a Edelman ${ }^{18}$, existe un

13. ARON, Raymund: "Macht, Power, Puissance”. En su: "Etudes Sociologiques". París, PUF, 1988. Págs. 50 y 43-67.

14. ARON, Raymond: Op. Cit.

15. GIBERTI, Eva y FERNÁNDEZ, Ana María (Comp.): Op. Cit.

16. CALVI, Bettina: Abuso Sexual en la Infancia: Efectos psíquicos ( $1^{\mathrm{a}} \mathrm{ed}$.). Buenos Aires, Lugar Editorial, 2006.

17. MARTÍN-BARÓ, Ignacio: "El trauma psicosocial”. En su: Psicología social de la guerra: Trauma y terapia. El Salvador, UCA Editores, 1992. Págs. 77-84.

18. EDELMAN, Lucila: "Apuntes sobre la memoria individual y la memoria colectiva”. En: Kersner, Daniel, Madariaga, Carlos, Aurelio, Marco y Martín, Aldo (Editores): Paisajes del dolor, senderos de esperanza. Buenos Aires, Editorial Polemos y EATIP, GTNM/RJ, CINTRAS \& SERSOC, 2002. Págs. 215-223.

Revista de Ciencias Sociales - Número 62 (2013) - Universidad de Valparáíso - ISSN 0716-7725-Valparáiso, Chile 
tipo de memoria individual conformada por la estratificación en el aparato psíquico de huellas mnémicas, las cuales se gestan a partir de acontecimientos con determinadas características de afecto y representación, y es sobre éstas que se efectuaría la represión puesto que están cargadas de una angustia intolerable para la persona.

Otro aspecto que es interesante de destacar en este tipo de memoria, es que confiere al sujeto la capacidad de resignificar, es decir, darle un sentido determinado a un acontecimiento del pasado en función de uno del presente.

Sin desmedro de lo anterior, según Maurice Halbwachs ${ }^{19}$, la memoria individual también se halla ligada a una memoria colectiva, la cual se caracteriza por ser un proceso social en el que se reconstruye lo vivido y experimentado por un cierto grupo, comunidad y/o sociedad. Además, siguiendo al mismo autor, asegura su identidad, naturaleza y valor de éste, por lo que este tipo de memoria es un "entretejido de tradiciones y memorias individuales" ${ }^{20}$.

En relación al incesto, es importante tener presente lo enunciado por Todorov ${ }^{21}$, quien manifiesta la existencia de una memoria literal, la cual permite mantener el evento traumático en su forma pura, inicial, como una visión estática del pasado que posibilita establecer causas efectos, y permite la continuidad entre el pasado y el presente de los individuos o comunidades. En este sentido, el acto de agresión sexual en su más puro acontecer. Esto, provocaría no sólo los síntomas propios del abuso sexual infantil como pérdida de la voluntad, vergüenza, temor e incredulidad ${ }^{22}$, sino que también la presencia de una memoria impedida, herida, producto del trauma y la rememoración de éste ${ }^{23}$.

19. HALBWACHS, Maurice: La Memoria Colectiva. Zaragoza, Prensas Universitarias de Zaragoza, 2004.

20. JELIN, Elizabeth: Los trabajos de la memoria. España, Siglo Veintiuno editores, 2002. Pág. 22.

21. TODOROV, Tzvetan: Los abusos de la memoria. Barcelona, Paidós Ibérica, 2008.

22. BARUDY, Jorge: Op. Cit. y CALVI, Bettina: Op. Cit.

23. RICOEUR, Paul: La memoria, la historia, el olvido. Buenos Aires, Fondo de Cultura Económica, 2004.

Facultad de Derecho y Ciencias Sociales - Universidad de Valparaíso - Chile 
En sintonía con lo anterior, un concepto que se liga con las ideas planteadas por Todorov y Ricoeur es el de olvido, el cual "se genera en la medida que los marcos de la memoria desaparecen" 24 . Es importante destacar que marco de memoria, se refiere tanto al tiempo como al espacio. Por tanto, siguiendo a Jelin, "el olvido entonces, no es una ausencia, si no la representación de algo que ahora no está, que se ha borrado, silenciado y negado" 25 . En este sentido, existe una voluntad del silencio determinada por la intención de "guardar las huellas encerradas en espacios inaccesibles, para cuidar a los otros, como expresión del deseo de no herir ni transmitir sufrimientos" ${ }^{26}$. El mismo silencio que el padre obliga a mantener a la hija frente a la situación abusiva, esperando que ésta no recuerde la situación esperando que el tiempo borre el trauma.

Finalmente, es necesario indicar que para producir la restauración psíquica de las personas que han sufrido cualquier tipo de abuso, incluido el incesto, es necesario recurrir a un proceso de reparación psicosocial, mediante el cual un trauma producido en el aparato psíquico, comienza a sanar, lo que se traduce en una recuperación del estado alterado; convirtiendo al afectado ya no en víctima, sino en un sobreviviente capaz de integrar la catástrofe a su historia de vida pudiendo usarla como un recurso ${ }^{27}$.

\subsection{E1 aspecto jurídico}

La Constitución chilena menciona en su artículo $19^{\circ}$ inciso 1 , que "Se asegura a todas las personas el derecho a la vida y a la integridad

24. HALBWACHS, Maurice: Los marcos sociales de la memoria. Barcelona, Anthropos, 2004b. Pág. 172.

25. JELIN, Elizabeth: Op. Cit. Pág. 28.

26. Ibíd. Pág. 31.

27. BANDERAS, Daniela: La experiencia musical como parte del proceso de reparación en mujeres víctimas de agresión sexual. Tesis para optar al grado de

Magíster en Artes, mención Musicología, Facultad de Artes, Santiago, Universidad de Chile, 2006.

Revista de Ciencias Sociales - Número 62 (2013) - Universidad de Valparaíso - ISSN 0716-7725-Valparaíso, Chile 
física y psíquica". Concordante con el concierto internacional, la Declaración Universal de Derechos Humanos señala, en su artículo $3^{\circ}$, que "Todo individuo tiene derecho a la vida" y la Convención Americana de los Derechos Humanos manifiesta, en su artículo $4^{\circ}$, que "Toda persona tiene el derecho a que se respete su vida [...] Nadie puede ser privado de la vida arbitrariamente".

Por otra parte, en relación al término de incesto tratado en los apartados anteriores y que da sustento al presente ensayo, el Código Penal chileno señala en su Artículo 375 lo siguiente:

"El que, conociendo las relaciones que lo ligan, cometiere incesto con un ascendiente o descendiente por consanguinidad o con un hermano consanguíneo, será castigado con reclusión menor en sus grados mínimo a medio".

Retomando los aspectos referentes al concepto de Derecho a la Vida, es preciso hacer hincapié que éste se debe entender como aquel "derecho a que no nos maten arbitrariamente" 28 . Por tanto, no se está frente a un derecho de dominio como el de propiedad sobre algún bien o cosa, sino que frente a uno que puede oponerse a toda persona que me agrede injustamente y que habilita la legítima defensa ${ }^{29}$. En este sentido, si una persona muere sin que se la mate arbitrariamente, es decir, de modo justificado como sería en legítima defensa, no se vulnera su derecho a la vida ${ }^{30}$.

Ahora bien, cabe preguntarse entonces ¿A qué se refiere el ordenamiento jurídico con la figura de legítima defensa? Una primera aproximación a la respuesta viene dada por la circunstancia de la acción de defenderse, donde se consideran principalmente las intenciones del

28. FIGUEROA, Rodolfo: "Concepto de Derecho a la Vida". En: Ius et Praxis, $\mathrm{N}^{\circ}$ 1, año 14, 2008. Pág. 262.

29. MARTÍNEZ, Andrea: Derecho a la vida y su relación con un presunto derecho a la muerte y de disposición del cuerpo humano. Memoria para optar al Grado de Licenciado en Ciencias Jurídicas y Sociales, Valdivia, Universidad Austral de Chile, 2003.

30. FIGUEROA, Rodolfo: Op. Cit.

Facultad de Derecho y Ciencias Sociales - Universidad de Valparaíso - Chile 
actor y no, necesariamente, los efectos de su potencial acto ${ }^{31}$. En este sentido, en el caso de legítima defensa, lo que busca el sujeto es defender su propia integridad (u otros bienes jurídicos de especial relevancia) y para ello, es inevitable atentar en contra de la vida de quien le agrede. En este punto, al respecto, es interesante lo mencionado por Santo Tomás de Aquino en su Summa Theológica:

\begin{abstract}
"Del acto de la persona que se defiende a sí misma pueden seguirse dos efectos: uno, la conservación de la propia vida; y otro, la muerte del agresor. Tal acto, en lo que se refiere a la conservación de la propia vida, nada tiene de ilícito, puesto que es natural a todo ser conservar su existencia todo cuanto pueda. Sin embargo, un acto que proviene de buena intención puede convertirse en ilícito si no es proporcionado al fin. Por consiguiente, si uno, para defender su propia vida, usa de mayor violencia que la precisa, este acto será ilícito [...] No es, pues, necesario para la salvación que el hombre renuncie al acto de defensa moderada para evitar ser asesinado, puesto que el hombre está más obligado a mirar por su propia vida que por la vida ajena"32.
\end{abstract}

Otro aporte interesante en relación a este fenómeno y recogido por Tórtora en su texto, alude al filósofo alemán Immanuel Kant, quien sostiene que "la defensa que se procura el absuelto nace de su propia necesidad de proteger su vida, pero que aquello no convierte en justa su conducta, sino que queda inmune de castigo sólo porque la necesidad no tiene ley y la represión se tornaría inútil" 33 .

Es importante no perder de vista en este caso, que frente a una situación de legítima defensa, sea o no con resultado de muerte, quien ejerce la acción no ha cometido ninguna otra para alejarse del marco

31. TÓRTORA, Hugo: "Las limitaciones constitucionales al derecho a la vida". En: Revista de Derechos Fundamentales, No 3, 2009. Págs. 175-201.

32. SANTO TOMÁS DE AQUINO: Suma Teológica. Segunda Sección de la Segunda Parte, Cuestión 64 "El homicidio". Artículo 7 ¿Es lícito a alguien matar a otro en defensa propia?, s/f, Recuperado el 17 de junio de 2012 de, http:// hjg.com.ar/sumat/c/c64.html Revisado el día 31 de diciembre de 2007. S/p.

33. TÓRTORA, Hugo: Op. Cit. Pág. 190.

Revista de Ciencias Sociales - Número 62 (2013) - Universidad de Valparáíso - ISSN 0716-7725-Valparaíso, Chile 
jurídico. Es más, son las circunstancias que lo impelan a apropiarse de la vida de un tercero puesto que debe proteger su propio bien. Por tanto, siguiendo lo enunciado por Tórtora, "la vida del agresor, que ha dejado de ser un derecho amparable por el Estado, le sirve de herramienta al agredido para defender la suya propia"34.

Cabe destacar, entonces, que el concepto de legítima defensa no ampara una respuesta desproporcionada frente a una agresión, no se trata de repeler un ataque con un cuchillo utilizando un tanque. Por tanto, debe ser proporcional e implica que lo que se defiende sea la propia persona del ofendido, sus bienes o derechos [su vida, integridad física, castidad, honor, pudor, etc. $]^{35}$.

En sintonía con lo anterior, se puede mencionar que el Código Penal en el artículo 10 alude y exige la proporcionalidad de las fuerzas bajo la premisa que exista una "necesidad racional del medio empleado para impedirla o repelerla”, que de ser efectiva exenta de responsabilidad criminal a quien se defienda.

Ahora bien, para que la dilución de responsabilidad penal sea plausible Novoa plantea en su texto dos puntos importantes a considerar: "a) que no haya otra manera o forma de proteger el bien jurídico agredido, y b) que entre los medios posibles elija el defensor aquel que sea suficiente, desechando el superfluo" 36 . De lo contrario, aún cuando se busque garantizar la defensa del ofendido, el acto de legítima defensa se vuelve una agresión y, por tanto, pudiere traer consecuencias legales en perjuicio de quien la ejerce.

Otro aspecto que pudiere, en algún punto, estar ligado al acto de legítima defensa guarda relación con la figura delictual de Encubridor y Cómplice. Razón por lo cual, se cree pertinente aclarar dichos términos en función del análisis de la película.

Se considera a una persona como Encubridor cuando de un modo u otro "procura la impunidad del crimen o delito, por actos posteriores a su

\footnotetext{
34. Ibíd. Pág. 191.

35. NOVOA, Eduardo: Curso de Derecho Penal Chileno. Santiago, Editorial Jurídica de Chile, 2005.

36. Ibíd. Pág. 342.
}

Facultad de Derecho y Ciencias Sociales - Universidad de Valparaíso - Chile 
comisión" $"$. Ahora bien, se puede facilitar la impunidad de diferentes formas, pero para efectos de este trabajo cobra especial importancia lo señalado en el Artículo 17, inciso 2 del Código Penal dado que es precisamente lo que realiza Raimunda al enterarse de la muerte de Paco: "Ocultando o inutilizando el cuerpo, los efectos o instrumentos del crimen o simple delito para impedir su descubrimiento".

A pesar de lo anterior, cabe señalar que el Código Penal menciona en el mismo artículo 17 que "están exentos de las penas impuestas a los encubridores los que lo sean de su cónyuge o de sus parientes legítimos por consanguinidad o afinidad en toda la línea recta y en la colateral hasta el segundo grado inclusive, de sus padres o hijos naturales o ilegítimos reconocidos".

Finalmente, el término Cómplice, según el artículo 16 del Código Penal, alude a todos quienes "cooperan a la ejecución del hecho [delictual] por actos anteriores o simultáneos”. A su vez, es esencial que no sólo se relacionen los actos ejecutados por el autor y los que se le atribuyen a la persona a quien se califique de cómplice, sino que es preciso, además, que ésta "con conocimiento del propósito criminal, coopere con intención de ayudar material o moralmente a la comisión del delito de un modo eficaz" 38 .

\section{Análisis en contraste con el film}

La película Volver $^{39}$ muestra la estrecha relación existente entre abuso de poder y violencia, reflejada en uno de los fenómenos más crudos y que revisten mayor daño para el psiquismo infantil como lo es una agresión sexual. En este sentido, las palabras de Marie-France Hirigoyen cobran sentido al sostener que "a lo largo de la vida,

37. RUIZ, Guillermo: Repertorio de Legislación y Jurisprudencia Chilenas. Código Penal y leyes complementarias. Santiago, Editorial Jurídica de Chile, 1995. Pág. 49.

\section{Ibíd. Pág. 48.}

39. ALMODÓVAR, Pedro (Director): Volver [Película], España, Video/DVD, 2006.

Revista de Ciencias Sociales - Número 62 (2013) - Universidad de Valparáíso - ISSN 0716-7725-Valparáiso, Chile 
mantenemos relaciones estimulantes que nos incitan a dar lo mejor de nosotros mismos, pero también mantenemos relaciones que nos desgastan y que pueden terminar por destrozarnos. Mediante un proceso de acoso moral, o de maltrato psicológico, un individuo puede conseguir hacer pedazos a otro" ${ }^{\prime 0}$. La hija entrega su confianza, integridad y resguardo a su padre, quien mediante el incesto se encarga de romper en pedazos su vida e infancia.

Por otra parte, el film retrata cómo la conducta perversa de un padre incestuoso, se transforma progresivamente en un actuar que trae "graves consecuencias para la salud psicológica de las víctimas [quienes] al no tener la seguridad de que serán comprendidas, callan y sufren en silencio" ${ }^{41}$. Esto último, se expresa con mayor fuerza en la figura de Raimunda, ya que es su propio padre quien comete incesto con ella y producto de esa relación nace Paula, de quien Paco quiso abusar. Por tanto, el silencio, el desconocimiento de la situación por parte de Irene, madre de Raimunda, y el miedo a que la historia ocurriese otra vez, son complejos entramados que perduran en la vida adulta de la protagonista, pero de manera subterránea.

Ahora bien, para comprender el sufrimiento de Raimunda, es importante tener presente que los sujetos que realizan incesto son perversos, es decir, "necesitan rebajar a los otros para adquirir una buena autoestima y, mediante ésta, adquirir el poder, pues están ávidos de admiración y de aprobación. No tienen ni compasión ni respeto por los demás, puesto que su relación con ellos no les afecta. Respetar al otro supondría considerarlo en tanto que ser humano y reconocer el sufrimiento que se le inflige" 42 .

Por otra parte, si se analiza la relación de Raimunda y Paco se puede sostener que ésta era complicada y problemática. Ello, motivado principalmente por el alcoholismo de éste; su poco interés en trabajar y su constante demanda sexual, que origina como resultado que sea ella

40. HIRIGOYEN, Marie-France: El acoso moral. El maltrato psicológico en la vida cotidiana. Barcelona, Paidós, 1999. Pág. 7.

41. Ibíd. Pág. 13.

42. Ibíd. Pág. 9.

Facultad de Derecho y Ciencias Sociales - Universidad de Valparaíso - Chile 
quien asuma el peso y responsabilidad de las tareas, como también la economía del hogar.

Es en esa dinámica antes descrita que Paco, una vez que se encuentra solo con Paula en la casa, intenta violarla, pero ésta al ver amenazada su integridad física y psíquica, se defiende y, en primera instancia, lo amedrenta con un cuchillo. Sin embargo, éste, al no mostrar interés en deponer sus intenciones y considerando que su hija sería incapaz de provocarle daño alguno, acomete con mayor insistencia y ella, dado que no dispone de otra alternativa, lo apuñala y asesina en legítima defensa para proteger su honra. Cuando llega su madre y descubre el hecho, decide esconder el cadáver para que su hija no deba enfrentarse a la policía, aunque antes le cuenta que él no era su verdadero padre, pero que en otro momento le dirá toda la verdad.

El hecho recién descrito, abre las puertas para hablar de un tema relevante en lo que respecta a memoria: Cripta traumática. Este concepto, alude al momento cuando los padres son traumatizados y no han elaborado dicha experiencia, lo cual se convierte en un secreto sin ningún significado en el inconsciente. Por tanto, son incapaces de reconocer, integrar y elaborar dicho trauma originándose una fractura en la continuidad psíquica de la persona.

Lo anterior, implica que existan áreas no reconocidas de este trauma que se transforman en objetos parcialmente simbolizados generando una cripta psicológica, la cual es transmitida a los hijos. Si bien, ellos no tienen acceso directo al evento en cuestión, existe una falta de conocimiento específico que crea en los descendientes un fantasma respecto a lo ocurrido, provocando en el resto que el evento sea in-hablable en la primera generación e in-nombrable en la segunda, creando un hueco simbólico mediado por la prohibición de hacerlo consciente, y por ende, develarlo ${ }^{43}$.

Finalmente, volviendo a la experiencia vivida por Raimunda y Paula, en relación con lo planteado por Tisseron y sus colaboradores ${ }^{44}$,

43. TISSERON, Serge, TOROK, Maria, RAND, Nicholas, NACHIN, Claude, HACHET, Pascal y ROUCHY, Jean Claude: El psiquismo ante la prueba de las generaciones. Buenos Aires, Amorrortu, 1995.

44. Ibíd.

Revista de Ciencias Sociales - Número 62 (2013) - Universidad de Valparáíso - ISSN 0716-7725-Valparaíso, Chile 
se puede sostener que existe un hueco simbólico producto del silencio de la madre frente a su experiencia, reflejado en el trauma encriptado que la aqueja. El haberse repetido el hecho abusivo con Paula, y ésta al enfrentarlo y decirlo, permite que el tema vuelva a ser $<$ hablado $>$, por tanto, deja de ser un tabú para la hija. El romper esta cripta, le permite a Raimunda decirle a Paula que efectivamente Paco no era su padre y, a su vez, posibilita la reconciliación con Irene, generando una restitución tanto en el orden de la palabra como en el genealógico.

\section{Discusión}

Antes de comenzar la discusión sobre los argumentos y el análisis del presente ensayo, es importante considerar un punto que pudiera causar diferencias en este aspecto. Esto último, debido a que la película de Almodóvar fue rodada en España. No obstante, la escena en cuestión que da origen al análisis de este trabajo se puede aplicar a cualquier país, en este caso Chile.

Concretamente, el apartado anterior, alude al intento de incesto que sufrió Paula por parte de Paco y la actitud que tuvo Raimunda al momento de descubrir el cuerpo de su marido en la cocina. A su vez, se puede sostener que el acto en sí mismo, a pesar de ocurrir en países distintos, no es impedimento de análisis debido a lo que sostiene Ferro, ya que una película es también un objeto cultural de la sociedad que la produce, así como de la que la recibe. Por tanto, se conforma desde diferentes frentes, realidades y subjetividades ${ }^{45}$.

En relación al incesto, se puede sostener que éste es un ataque a la honra de la persona, que encuentra su asidero en el documento Actas Oficiales de la Comisión Constituyente Sesiones $129^{a}$ y $130^{a}$ de la República de Chile. En este caso, siguiendo a los señores Jorge Ovalle Quiroz y Jaime Guzmán Errázuriz, se puede sostener que dicho término alude a la "estima y respeto de la dignidad propia", donde el segundo agrega que "la intimidad envuelve el ámbito de una zona de la vida de la persona

45. FERRO, Marc: "El cine: Agente, producto y fuente de la historia”. En su: Diez lecciones sobre la historia del siglo XX. México, Siglo Veintiuno Editores, 2009. Págs. 105-119.

Facultad de Derecho y Ciencias Sociales - Universidad de Valparaíso - Chile 
que debe quedar excluida de la noticia o de la invasión externa" y es, precisamente, esto último lo que hace el incesto; invadir a la persona no sólo en su espacio físico, sino también en el psíquico y social ${ }^{46}$.

Por otra parte, siguiendo el Pacto de San José de Costa Rica, el acto de Paco constituye una violación al artículo $11^{\circ}$ inciso 1 de dicho documento puesto que "Toda persona tiene derecho al respeto de su honra y al reconocimiento de su dignidad", y es precisamente la honra de Paula, adjunta a la de su linaje y familia, la que se ve menoscabada en dos dimensiones: 1) Frente al posible éxito de la agresión y 2) Potencialidad y consecuencias del acto. Razón por lo cual, se ve forzada a defenderse utilizando como primera opción la mediación y al no obtener el resultado esperado, un cuchillo.

En sintonía con lo tratado en el párrafo anterior, la Declaración Universal de Derechos Humanos sostiene en su artículo 12 que "nadie será objeto de injerencias arbitrarias en su vida privada [...] ni de ataques a su honra o a su reputación. Toda persona tiene derecho a la protección de la ley contra tales injerencias o ataques".

Con el objetivo de entregar una visión más amplia a la situación previa que vivió Paula al intento de agresión sexual efectuado por Paco, el término acuñado por William Prosser ${ }^{47}$, denominado Intrusion resulta de gran utilidad. Esto, porque dicho concepto se puede entender como la intromisión en la soledad física que cada persona se ha reservado. En este caso específico, se pueden considerar las actitudes de Paco como un acoso irrazonable al círculo íntimo de su potencial víctima; si bien no la grabó o introdujo micrófonos en su habitación, sí la espió en alguna ocasión.

Finalmente, respecto al trauma que produjo en Paula la situación acontecida y el silencio guardado por Raimunda ante su propia vivencia de abuso, es importante sostener que desde una perspectiva psicosocial,

46. Citados en MEDINA, Cecilia y MERA, Jorge (Eds.): Sistema Jurídico y Derechos Humanos. El derecho nacional y las obligaciones internacionales de Chile en materia de Derechos Humanos, Cuadernos de Análisis Jurídico, Serie publicaciones especiales. Santiago, Escuela de Derecho Universidad Diego Portales, 1996, Pág. 570.

47. PROSSER, William: "Privacy [a legal analysis]". En: California Law Rewiew, No 48, 1960. Págs. 338-423.

Revista de Ciencias Sociales - Número 62 (2013) - Universidad de Valparáíso - ISSN 0716-7725-Valparaíso, Chile 
no se puede elaborar una experiencia traumática sin reconocer lo perdido ni hablar de lo ocurrido, lo cual facilita la cicatrización de las heridas, ya sean éstas sociales, psíquicas o de otro orden ${ }^{48}$. Por tanto, en ningún caso es recomendable la llamada terapéutica del olvido que sólo busca "evitar asumir responsabilidades" ${ }^{49}$ por parte de quienes han causado daño. Por tanto, un avance significativo y reparador en este aspecto, es precisamente la reconciliación de Raimunda con Irene y la develación que Paco no es el padre de Paula.

\section{Conclusiones}

Para que sea posible la ocurrencia del incesto es de vital importancia considerar, al margen de factores facilitadores e ideas de madres negligentes abundantes en la literatura ${ }^{50}$, el conjunto de entramados sociales que determinan las relaciones entre los seres humanos en tanto personas sexuadas, siendo el par subordinación femenina-dominación masculina el más usual conocido como Sistema Sexo Género ${ }^{51}$.

Dicho sistema, definido como "el conjunto de disposiciones por el que una sociedad transforma la sexualidad biológica en productos de la actividad humana y en el que se satisfacen esas necesidades humanas transformadas" ${ }^{2}$, es el que junto a una idiosincrasia patriarcal permite

48. FOUCE, José: “La memoria histórica cierra heridas”. En: Fouce, José y Parisí, Elio (Comp.): Psicología para otro mundo posible. Tucumán, Ediciones Cooperativas, 2008. Págs. 89-91.

49. Ibíd. Pág. 89.

50. MARCHANT, Juan Paulo y SOTO, Evelyn: "Reaccions maternes inusuals enfront del incest patern - filial. Una mirada analògica des de l'anàlisi de la pel.lícula 'Volver”. En: Revista d'Estudis de la Violència, No 8, 2009, s/p.

51. DE BARBIERI, Teresa: "Sobre la categoría género. Una introducción teóricometodológica”. En: Ediciones de Las Mujeres, No 17, Isis Internacional, 1991. Págs. 111-128.

52. Ibíd. Pág. 114.

Facultad de Derecho y Ciencias Sociales - Universidad de Valparaíso - Chile 
la instauración del imaginario de mujer-objeto. Por tanto, su visualización como producto para satisfacer al hombre, con especial atención en lo que al ámbito sexual se refiere. Es en esta dinámica, donde la posibilidad del incesto se transforma en uno de los potenciales ataques que deberá enfrentar la mujer a lo largo de su vida.

Dado lo anterior, frente a una situación incestuosa y desde lo colectivo, la primera responsable es la madre al haber fallado en el cuidado de su hija. Es más, tradicionalmente se tiende a culpabilizarlas con frases del tipo: <ella lo debe haber sabido>, <ella lo permitió $>$ o <cómo no se dio cuenta $>{ }^{53}$, lo cual deja en evidencia el sesgo paternalista de la sociedad, puesto que la culpa del padre se proyecta en ella, se aminora e incluso, se diluye u omite. Esto último, guarda relación con la terapéutica del olvido enunciado por Fouce en su texto ${ }^{54}$.

Respecto a la hipótesis que se barajó a lo largo de este trabajo, que guarda relación con que la prohibición de develar el incesto sostiene el establecimiento de una cripta que opera como escalada de violencia y complicidad frente a posibles ataques, se puede mencionar que en aquellas situaciones donde no se otorga contención y se desarrolla un trabajo terapéutico así como tampoco, se brindan las herramientas para lograr una adecuada reparación psicosocial de la persona afectada, sumado al silencio de la víctima, el establecimiento de la cripta es válido.

Ahora bien, no se puede afirmar, sin lugar a duda razonable, que el mero establecimiento de la cripta traumática dé pie, ipso facto, a una escalada de violencia en miras de la resistencia que podría interponer la víctima, ya que ésta suele paralizarse frente a lo ocurrido. En cambio, sí se puede sostener que se produce una escalada de violencia por parte del agresor dado que éste tiene a su haber un mayor número de mecanismos coercitivos para que el silencio perdure en el tiempo, como el chantaje y distorsión de la realidad.

Por otra parte, no es posible hablar de complicidad frente a este tipo de situación. Ello, debido a que la cronificación de la dinámica

\footnotetext{
53. MARCHANT, Juan Paulo y SOTO, Evelyn: Op. Cit.

54. FOUCE, José: Op. Cit.
}

Revista de Ciencias Sociales - Número 62 (2013) - Universidad de Valparáíso - ISSN 0716-7725-Valparaíso, Chile 
abusiva, es decir, el tiempo en que la víctima demora en detener y denunciar el acto en cuestión, se encuentra mediado por el sometimiento, sensación de indefensión, manipulación y anulación de su voluntad y libertad ${ }^{55}$. Por tanto, las posibilidades de salir de la situación se minimizan. A su vez, esto último, el pensar a la víctima como cómplice del abuso o pseudo facilitador, vuelve a traer consigo la impronta patriarcal de la sociedad así como, las viejas tretas de $<$ le gustaba, me buscaba o se insinuó $>$. No obstante, siempre se debe tener presente que una víctima de agresión sexual no es cómplice de ésta.

En relación al concepto de legítima defensa con resultado de muerte ante situaciones de agresión sexual, específicamente el caso analizado, Paula intenta defender su derecho a la honra, pudor y castidad $^{56}$. Ahora bien, dado que el Código Penal exige en el artículo 10 que exista una "necesidad racional del medio empleado para impedirla o repelerla", se puede considerar que la forma en que se presenta la situación en la película se ajusta al Derecho.

Lo anterior, debido a que Paula primero intenta establecer un diálogo con su agresor y cuando éste se torna fútil, el único elemento o herramienta a la cual puede recurrir para proteger su bien preciado es la utilización de la fuerza, en este caso, mediada por el cuchillo de cocina. Por tanto, es concordante con lo expuesto por Novoa dado que no contaba con "otra manera o forma de proteger el bien jurídico agredido" y puesto que el diálogo no obtuvo frutos, considerando el legítimo instinto de sobrevivencia, optó por aquel medio "que sea suficiente" 57.

Por otra parte, según lo expuesto hasta el momento, pudiere existir un acto que sí podría imputarse a Paula guarda relación con la denegación de auxilio, ya que una vez herido Paco ella no ejerce acción alguna para paliar, o bien, remediar su dolor. En este sentido, no llama a un servicio de ambulancia o fuerza policial, lo deja en el piso. No obstante, dado el impacto de lo vivido y el fuerte componente afectivo

55. MARCHANT, Juan Paulo: Iglesia, Género y Poder. El Caso Karadima. Saarbrücken, Alemania, Editorial Académica Española - EAE, 2012.

56. NOVOA, Eduardo: Op. Cit. MEDINA, Cecilia y MERA, Jorge: Op. Cit.

57. Ambas citas corresponden a NOVOA, Eduardo: Op. Cit. Pág. 342.

Facultad de Derecho y Ciencias Sociales - Universidad de Valparaíso - Chile 
que implicó la situación, la actitud adoptada es comprensible si se aborda como paralización frente al miedo y situaciones angustiantes, más que como una acción dolosa o vengativa.

Otro aspecto que llama la atención en este film, es el papel que desenvuelve Raimunda al descubrir el cuerpo de Paco. Esto, dado que en primera instancia se podría considerar que ella es encubridora de su hija, ya que esconde el cuerpo facilitando "la impunidad del crimen o delito, por actos posteriores a su comisión" ${ }^{58}$. Sin embargo, lo señalado en el artículo 17 del Código Penal chileno menciona que "están exentos de las penas impuestas a los encubridores los que lo sean de su cónyuge o de sus parientes legítimos por consanguinidad o afinidad en toda la línea recta y en la colateral hasta el segundo grado inclusive, de sus padres o hijos naturales o ilegítimos reconocidos".

Lo anterior, agrega la misma disposición, siempre que éstos no faciliten a los delincuentes "medios para que se aprovechen de los efectos del crimen o simple delito". Considerando esto último, cabe preguntarse entonces ¿Cuál es el bien que obtiene Paula?, ¿Cómo el actuar de Raimunda originaría un aprovechamiento por la muerte de Paco, ya sea personal o de su hija?

En primera instancia, no se puede sostener que Paula obtiene como ganancia de su actuar su honra, esto dado que siempre fue suya. Es más, era otro quien quería arrebatársela por lo que esgrimir que el beneficio es el mantenimiento de su honor, sería un despropósito. No se puede < ganar o aprovechar $>$ un bien jurídico que ya se posee.

Respecto al acto de Raimunda, en la película no se evidencia que haya usufructuado de los bienes del marido, es ella quien sostiene el hogar. A pesar de ello, se podría elucubrar que una ganancia, simbólica si quiere verse desde esa línea, es que su hija continúa a su lado y que ha podido revelarle parte del secreto que en silencio la atormenta, aunque esto es un hecho difícil de probar ante un Tribunal y que no guarda relación directa con la muerte de Paco. Por tanto, considerando estos planteamientos, no cabría la posibilidad de adjudicarle la figura de encubridora a Raimunda por proteger a su hija.

58. RUIZ, Guillermo: Op. Cit.

Revista de Ciencias Sociales - Número 62 (2013) - Universidad de Valparáíso - ISSN 0716-7725-Valparaíso, Chile 
Un punto importante desde el bienestar psicológico y familiar que vale la pena destacar, es el vínculo de confianza que se establece entre Raimunda y Paula, donde se ve un polo totalmente opuesto a su historia vital, ya que es la madre quien le brinda a su hija un ambiente de seguridad, protección, apoyo y comprensión.

Finalmente, para concluir, cabe mencionar que este trabajo no busca promover el asesinato de potenciales sujetos incestuosos, sino que centrar su atención en una dinámica que pudiera replicarse en Chile y, al mismo tiempo, entregar una visión más amplia de los posibles efectos jurídicos que pudieran originarse por este hecho. Cabe mencionar, eso sí, que si bien Volver es producto del contexto socio-cultural español, en el cual la imagen de la mujer emerge más fortalecida en contraposición a la chilena, el móvil de proteger a un hijo frente a la adversidad no responde a limitaciones geográficas.

\section{Bibliografía}

ABARZA, Pamela y OLIVARES, Alejandra, "Estudio exploratorio descriptivo de interacciones del sistema familiar en familias con abuso sexual infantil", Tesis para optar al título de psicólogo, Facultad de Ciencias Sociales, Santiago, Universidad de Chile, 2000.

ALMODÓVAR, Pedro (Director), "Volver" [Película], España, Video/DVD, 2006.

ARON, Raymund, Macht, Power, Puissance. En su: "Etudes Sociologiques", París, PUF, 1988, pp. 43-67.

BANDERAS, Daniela, "La experiencia musical como parte del proceso de reparación en mujeres víctimas de agresión sexual", Tesis para optar al grado de Magíster en Artes, mención Musicología, Facultad de Artes, Santiago, Universidad de Chile, 2006.

BARUDY, Jorge, "Maltrato Infantil, Ecología Social: Prevención y Reparación”, Santiago, Editorial Galdoc, 1998.

BECAR, Carolina e IBACETA, Francisco, "Abuso sexual incestuoso y sistema judicial: Obligatoriedad de la denuncia o estrategia y opción

de intervención psicosociolegal", Memoria para optar al título de psicólogo, Facultad de Ciencias Sociales, Santiago, Universidad de Chile, 2000.

Facultad de Derecho y Ciencias Sociales - Universidad de Valparaíso - Chile 
CALVI, Bettina, "Abuso Sexual en la Infancia: Efectos psíquicos”, $1^{\text {a }}$ ed., $1^{\text {a }}$ reimp., Buenos Aires, Lugar Editorial, 2006.

CAPELLA, Claudia y MIRANDA, Jennifer, "Diseño, implementación y evaluación piloto de una intervención psicoterapéutica grupal para niños y niñas víctimas de abuso sexual", Tesis para optar al título de psicólogo, Facultad de Ciencias Sociales, Santiago, Universidad de Chile, 2003.

CONNELL, Robert, La organización social de la masculinidad, En: Valdés, Teresa y Olavarría, José (Eds). "Masculinidades, Poder y Crisis", Santiago de Chile, Isis Internacional / FLACSO, 1997, pp. 31-48.

DE BARBIERI, Teresa, Sobre la categoría género. Una introducción teórico-metodológica. En "Ediciones de Las Mujeres”, No 17, Isis Internacional, 1991, pp. 111-128.

DUARTE, Diana, et. al, Análisis e interpretación de los resultados de un caso complejo de mezcla de ADN (incesto endogámico), Ponencia presentada en "III Congreso Brasilero de Genética Forense y II Jornada Latinoamericana de Genética Forense”, 10-13 de mayo, PUCRS, Porto Alegre, Brasil, 2011.

EDELMAN, Lucila, Apuntes sobre la memoria individual y la memoria colectiva. En: Kersner, Daniel, Madariaga, Carlos, Aurelio, Marco

y Martín, Aldo (Editores), "Paisajes del dolor, senderos de esperanza”, Buenos Aires, Editorial Polemos y EATIP, GTNM/RJ, CINTRAS \& SERSOC, 2002, pp. 215-223.

FERRO, Marc, El cine: Agente, producto y fuente de la historia. En su: "Diez lecciones sobre la historia del siglo XX", México, Siglo Veintiuno Editores, 2009, pp. 105-119.

FIGUEROA, Rodolfo, Concepto de Derecho a la Vida, en "Revista Ius et Praxis", No 1, año 14, 2008, pp. 261-300.

FOUCAULT, Michel, El sujeto y el poder, en "Revista Mexicana de Sociología", vol. 50, No 3, 1988, pp. 3-20.

FOUCAULT, Michel, "Vigilar y castigar: nacimiento de la prisión", $1^{\text {a }}$ ed. Buenos Aires: Siglo XXI Editores, 2002.

FOUCE, José, La memoria histórica cierra heridas. En: Fouce, José y Parisí, Elio, (Comp.), "Psicología para otro mundo posible”, Tucumán, Ediciones Cooperativas, 2008, pp. 89-91.

FREUD, Sigmund., "Tótem y tabú”, Madrid, Alianza, 1988. 
GIBERTI, Eva, (1998). “Incesto paterno-filial: una visión multidisciplinaria: perspectivas históricas, psicológicas, jurídicas y forenses", Buenos Aires, Editorial La Universidad, 1998.

GIBERTI, Eva y FERNÁNDEZ, Ana María (Comp.), "La mujer y la violencia invisible”, Buenos Aires, Editorial Sudamericana, 1989.

HALBWACHS, Maurice, "La Memoria Colectiva”, Zaragoza, Prensas Universitarias de Zaragoza, 2004a.

HALBWACHS, Maurice, "Los marcos sociales de la memoria”, Barcelona, Anthropos, 2004b.

HIRIGOYEN, Marie-France, "El acoso moral. El maltrato psicológico en la vida cotidiana", Barcelona, Paidós, 1999.

JELIN, Elizabeth, "Los trabajos de la memoria”, España, Siglo Veintiuno editores, 2002.

MARCHANT, Juan Paulo, "Iglesia, Género y Poder. El Caso Karadima", Saarbrücken, Alemania, Editorial Académica Española - EAE, 2012.

MARCHANT, Juan Paulo y SOTO, Evelyn, Reaccions maternes inusuals enfront del incest patern - filial. Una mirada analògica des de l'anàlisi de la pel.lícula "Volver", en "Revista d'Estudis de la Violència", No 8, 2009, s/p.

MARTÍN-BARÓ, Ignacio, El trauma psicosocial. En su: "Psicología social de la guerra: Trauma y terapia”, El Salvador, UCA Editores, 1992, pp. 77-84.

MARTÍNEZ, Andrea, "Derecho a la vida y su relación con un presunto derecho a la muerte y de disposición del cuerpo humano", Memoria para optar al Grado de Licenciado en Ciencias Jurídicas y Sociales, Valdivia, Universidad Austral de Chile, 2003.

MEDINA, Cecilia y MERA, Jorge (Eds), Sistema Jurídico y Derechos Humanos. El derecho nacional y las obligaciones internacionales de Chile en materia de Derechos Humanos, en "Cuadernos de Análisis Jurídico, Serie publicaciones especiales", Santiago, Escuela de Derecho Universidad Diego Portales, 1996.

NAVARRO, Carolina, "Patrones de vinculación en madres de víctimas de abusos incestuosos: Los peligros del vínculo", Tesis para optar al título de psicólogo, Facultad de Ciencias Sociales, Santiago, Universidad de Chile, 1998.

Facultad de Derecho y Ciencias Sociales - Universidad de Valparaíso - Chile 
NOVOA, Eduardo, "Curso de Derecho Penal Chileno", Santiago, Editorial Jurídica de Chile, 2005.

ORGANIZACIÓN DE ESTADOS AMERICANOS, "Convención Americana sobre Derechos Humanos. Pacto de San José de Costa Rica", Costa Rica, Sec. Gral. OEA, 1969.

PROSSER, William, Privacy [a legal analysis], en "California Law Rewiew", No 48, 1960, pp. 338-423.

QUIRÓS, Paula, "Comparación de las dinámicas familiares en familias que presentan abuso sexual con otros tipos de familia", Tesis para optar al grado de Magíster en Psicología, Facultad de Ciencias Sociales, Santiago, Universidad de Chile, 2006.

REPÚBLICA DE CHILE, "Código Penal”, Santiago, Ministerio de Justicia, 1874 [Última Modificación: 11-MAY-2012, Ley 20585].

REPÚBLICA DE CHILE, "Constitución Política de la República de Chile”, Santiago, Diario oficial de la República, 2005.

RICOEUR, Paul, "La memoria, la historia, el olvido", Buenos Aires, Fondo de Cultura Económica, 2004.

RUIZ, Guillermo, "Repertorio de Legislación y Jurisprudencia Chilenas. Código Penal y leyes complementarias", Santiago, Editorial Jurídica de Chile, 1995.

SANTO TOMÁS DE AQUINO, "Suma Teológica. Segunda Sección de la Segunda Parte, Cuestión 64 "El homicidio". Artículo 7 ¿Es lícito a alguien matar a otro en defensa propia?”, s/f, Recuperado el 17 de junio de 2012 de, http://hjg.com.ar/sumat/c/c64.html Revisado el día 31 de diciembre de 2007.

TISSERON, Serge, TOROK, Maria, RAND, Nicholas, NACHIN, Claude, HACHET, Pascal y ROUCHY, Jean Claude, "El psiquismo ante la prueba de las generaciones", Buenos Aires, Amorrortu, 1995.

TODOROV, Tzvetan, "Los abusos de la memoria", Barcelona, Paidós Ibérica, 2008.

TÓRTORA, Hugo, Las limitaciones constitucionales al derecho a la vida, en "Revista de Derechos Fundamentales", No 3, 2009, pp. 175-201.

UNESCO, "Declaración Universal de Derechos Humanos", Santiago, Oficina Regional de Educación de la UNESCO para América Latina y el Caribe, 2008. 